\title{
An Investigation on Moving Rural Secondary Schools to Town in New Countryside Construction: Taking Ling County in Shandong Province as An Example
}

\author{
Shuang Li \\ Department of Education, Dezhou University, Dezhou 253023, China \\ E-mail: Lishuang305@163.com
}

\begin{abstract}
Based on some problems lying in current rural secondary education taking Ling County as an example, this paper proves the necessity and feasibility of moving rural secondary schools to town in the current condition: it is an objective demand by the changes in students; it is a necessary demand to optimize resource allocation and to improve educational quality as well as to improve teachers' welfare and to optimize staff quality; it is a necessary demand to narrow the disparity between the urban and rural areas and to realize education equality; preferential national policies have offered guarantee for moving rural secondary schools to town; the improved rural conditions has provided it with basic guarantee; the physical and psychological characteristics of students in secondary schools have also provided precondition for it and the development of rural economics has also provided financial support.
\end{abstract}

Keywords: Rural secondary schools, Going to town, Investigation

For a long time, a three-level pattern including village-run primary school, county-run secondary school and senior high school has been adopted in China's rural educational administration system. It has made undeniable contributions for popularizing nine-year compulsory education as well as improving Chinese nation's quality in the recent decades especially after the reform and opening policy. In the recent years, with the construction of new countryside and the development of rural economy, rural parents have developed increasingly higher expectation for education and hope their children will enjoy the same excellent educational resources as those in cities and have brighter future. However, the lacking resources in countryside fail to satisfy such demands fundamentally. It is the key to this problem to integrate resources and adjust structure. Therefore, it seems quite necessary to explore how to adjust the current structure of rural secondary schools and try moving them to town in order to make it an effective pattern to solve the disparity between urban and rural education in developing areas.

\section{Major Problems in Current Rural Secondary Education}

\subsection{Its Structure with Multi Points, Long Line and Wide Range}

According to the survey on Ling County conducted by the author, there are only over ten middle schools all over the county, among which two are located in the central county while the others are in the suburban areas. Such a layout helps to popularize rural compulsory education since it offers great convenience for students in different counties due to the short distance to school. However, with the profound development of economy and educational reform, such a structure disperses the input in education and disturbs the systematic distribution of educational resources between urban and rural areas as well as schools, hence restricting the improvement of rural educational quality.

\subsection{The Lack of Excellent Teaching Staff Leading to Poor Educational Quality}

Due to some historical and realistic reasons, there is still a large disparity between urban teachers' treatment and that of rural ones, from which the imbalance and flow of teaching resources have resulted. At present, rural teachers going to town has become a trend. Those choosing to stay in countryside cannot keep up with the times in knowledge reserve and therefore are isolated from new ideas, methods and contents because they have no access to information. It is shown in some materials that $87.3 \%$ of the informants claim that teachers in rural secondary schools haven't established advanced educational ideas and still have a long way to go to satisfy the new curriculum requirements; $78.8 \%$ of the informants think that their poor teaching ability and aging structure make it inadaptable to new curriculum. According to some class surveys, a majority of teachers are snowed under with the burden of learning new curriculum, have quite limited studies on its curriculum system and have great difficulty in innovating the current teaching methods, hence producing poor teaching effect.

\subsection{Great Disparity in School Running Conditions between Urban and Rural Areas}

It is shown in our survey that the imbalance in educational resources allocation still restricts the development of 
China's basic education. For instance, in Ling Country of Shandong Province, excellent educational resources are located in the central part, such as Ling County Experimental Middle School which has three comprehensive buildings covering over $30000 \mathrm{~m}^{2}$ used for teaching, experiment and administration as well, equipped with languages labs, computer labs, multi-media classrooms and so on. However, most rural secondary schools have poor conditions, in which their computer labs, libraries, electro-chemical equipments and labs were bought to go through the examination of "popularizing nine-year compulsory education" and have low end equipment and suffer form severe damages.

\subsection{Severe Loss of Rural Secondary Students}

There are two major causes for the loss of students: first, more parents transfer their children to the schools in central county or city with the improvement of their income and increased emphasis on education; second, influenced by the currently severe employment situation, "uselessness of study" becomes popular again and some parents ask their children to drop out of school to find a job in central county or city. For example, in a village of Ling County, there were 230 secondary graduates in 2007, 153 fewer than those in 2003 and reaching a loss rate of $40 \%$. Such a severe loss has badly influenced the scale of rural secondary schools.

\subsection{Problems of the Children of Rural Migrant Workers}

Chinese population is in large-scale flow now with the speed-up of urbanization construction. During the course, the minor children of those rural migrant workers cannot go to town with their parents due to economic reasons or the restrictions of census registration system, hence producing such a special group which keeps expanded nowadays. These children, taken care of by their grandparents who care more for their daily life than their study, have poor behavioral habits especially learning habits. In addition, lacking in effective supervision from their families and parents, these children often infringe upon others or are infringed upon. In the author's investigation in three county middle schools, there are 45 empty nest families or skipped generation families, taking up $7 \%$ of the total. According to the statistics of China Supreme People's Court, this special group of children has committed $20 \%$ to $30 \%$ of the adolescents' crimes and its proportion is increasing every year (Liu, 2001).

\section{The Necessity of Moving Rural Secondary Schools to Town}

It is a necessary demand by the dynamic development of a variety of subjective and objective conditions to move rural secondary schools to town.

\subsection{An Objective Demand by the Changes in Students}

Education serves students, therefore, the structure of school should be adjusted according to the changes in the number of students. It is shown in our survey that many schools have smaller scale and some even fail to reach the standard issued by the Ministry of Education about class scale due to the reduced number of students. In Ling County, there are two major reasons for this current situation: first, the implementation of the birth control policy has cut down the number of rural students; second, more rural students go to town with the speed-up of urbanization. It is estimated by Jingmei Qi, an advanced economist in Department of Economic Prediction of National Information Center, that China's urbanization level will remain an annual increase of $1.3 \%$, its rate of urbanization will reach $49.8 \%$ and its urban population will reach $670,000,000$ and will be equal to its rural population for some time to come ( $\mathrm{Li}, 2003)$. Influenced by the macro environment, Ling County's urbanization level will be improved constantly in the following few years. As a result, more people will pour into cities, promoting more rural students to go to school there.

\subsection{A Necessary Demand to Optimize Resources Allocation and Improve Educational Quality}

It is the fundamental purpose of structure adjustment to optimize resources allocation and improve educational quality. With the development of social economy, the current small-scale and resources-dispersed school structure is leading to the disintegration of educational resources, excessive input and poor school-running profit, hence restricting the reform and development of the whole county's education. According to modern economic theories, the expansion of production scale and the reasonable allocation of resources will reduce production cost and increase profit in certain conditions. We should learn from this market rule to exert the advantage of integrated educational resources and improve educational quality and profit by optimizing educational structure and reasonably allocating educational resources. To be more specific, on one hand, the adjustment of school structure will achieve maximized profit of educational resources by reasonably allocating hard resources; on the other hand, it will effectively save soft resources and therefore lessen financial burden. In addition, such adjustment will integrate educational resources to form a concentrated educational resources group, which helps the transmission of educational information and the conduction of scientific and technological activities as well as the improvement of school-running conditions and the overall school-running level. 


\subsection{A Necessary Demand to Improve Teachers'Welfare and Optimize Teaching Staff's Quality}

Currently, although all teachers get paid by the county's financial authority, those teaching in villages have a salary over 100 yuan or even 200 and 300 yuan less than that of those teaching in county. Due to the differences in salary, life and work condition, some village teachers are dissatisfied with the current situation. Many excellent teachers are not willing to stay in rural areas, nor are newly-graduating college students, leaving rural education in a dilemma. With rural teachers moving to town along with their schools, the disparity between urban teachers and rural teachers' salary, work condition and so on are narrowed and therefore the man-oriented principle will be really realized and teachers' enthusiasm will be encouraged. Meanwhile, with teaching staff adjusted, substitute teachers can be removed, hence saving money and improving the overall quality of teaching staff a lot.

\subsection{A Necessary Demand to Narrow the Urban-Rural Gap and Realize Educational Equality}

Educational equality has long been regarded as a symbol of social harmony. In some sense, there is no social harmony without educational equality. However, there is no doubt that the resources the rural students have are incomparable to those of the urban students. Due to the shortage of resources, most rural secondary schools have a low rate of enrolment, hence encouraging more students to go to better schools in town. As a result, the number of students, especially excellent students going to rural secondary schools, is reduced gradually and so is the enrolment rate, hence producing a vicious cycle. As for spontaneous transfer, it hits the pockets of students and asks more for school's educational resources. With secondary schools moved to town, urban and rural students will enjoy the same educational conditions and resources, hence promoting educational equality and social harmony.

\section{The Feasibility of Moving Rural Secondary Schools to Town}

Many provinces and cities have conducted some beneficial explorations on reasonably adjusting rural secondary schools' structure, such as Tianjin, Zhejiang, Jiangxi and so on who have integrated some schools and therefore improved their school-running scale and benefit. According to the current situation of Ling County of Shandong Province, it is not only necessary but feasible to move rural secondary schools to town.

\subsection{National Preferential Policies on Compulsory Education Offering Policy Guarantee}

It is pointed out in China's Eleventh Five-Year Plan that greater emphasis should be attached to rural compulsory education, government's guarantee for compulsory education should be enhanced, central and provincial governments' transfer payments for compulsory education in those counties suffering from financial difficulty should be increased and government should be fully responsible for compulsory education (R \& D Center of Shanghai Academy of Educational Science, 2003). Obviously, China plans to increase its input in rural compulsory education and the transfer payments by central and provincial governments will offer powerful financial support for the construction of county secondary schools. In addition, it was issued in 2007 that the fees for compulsory education would be cancelled and in 2009 that the accommodation fees of the rural students would be cancelled as well. As a result, poor students will have less difficulty in going to school in town and will gain preferential support for their compulsory education.

\subsection{The Improvement of Rural Hard and Soft Conditions Offering Basic Guarantee}

Ever since the reform and opening, especially the recent years, China's rural economy has achieved rapid development. In 2005, the per capita GDP of Shandong exceeded 20000 yuan; peasants' per capita net income was 3930.6 yuan; the per capita GDP of Ling County exceeded 13000 yuan and the per capita net income of its peasants was increased to 3800 yuan compared with the sum of over 2000 yuan at the end of the Ninth Five-Year Plan, making it possible to increase the input in education. Ever since 2003, Shandong has conducted projects to construct roads and add buses which connect villages into a net. By the end of 2005, there had been buses among $98 \%$ of the villages in Ling County, creating quite convenient transportation. For example, it only takes half an hour to reach the central county from the most remote village. Therefore, it is quite convenient for students to go to school in town.

\subsection{Secondary Students' Physical and Psychological Characteristics Offering Preconditions}

In spite of their similarity, there are fundamental differences between secondary and primary schools. Ranging from 12 to 15 years old, most secondary students have got certain abilities of taking care of themselves and are adapted to their group life. In a phase of "the second birth of their personality", their sense of group and teamwork spirit will be cultivated and their independent abilities in life and learning can be improved through their group life, hence helping their healthy development. 


\subsection{Advanced Educational Administration in Central County Offering Powerful Support}

According to the learning theory of Constructivism, it is quite positive for the development of students to directly indulge students into urban new civilization and environment, new facilities and technologies. With the simple and laggard buildings, computer labs and experiment labs in their former rural schools, these students deeply experience the development of science, technology and the times when coming to the county middle school which is equipped with multi-media classrooms, language labs and electronic reading rooms. The constant improvement of teaching facilities helps to develop students' strong suits. In addition, when in rural schools, students are often distracted from their study due to the irregular management in school and at home. However, in county schools, with the universal boarding system and regular management, students' behavior, time arrangement, life and study are managed according to strict rules, helping them to develop good habits and to improve their comprehensive quality.

\subsection{The Development of County Economy Providing Financial Support}

Pingyuan County, next to Ling County, began to move its secondary schools to town in 2004. It expanded the junior section of Pingyuan No.1 Middle Schools with a scale of 10000 students and established a foreign language school, containing over 10000 secondary students in town. Having the total of 19000 secondary students and over 7400 ones in town now, Ling County needs to expand its secondary school scale to contain 12000 more students. With the similar geographical location and development in Ling County and Pingyuan County, they should have similar investment intensity. With its rapid-developing private economy with over 200 private businesses, Ling County has got quite solid financial basis for it input in education.

To sum up, it is an important measure to conduct Three Represents Theory, to improve rural educational quality and school-running benefit and to promote urbanization as well as a necessary choice to reasonably allocate educational resources, to promote educational modernization and even rural modernization. However, as a long-term and complicated systematic project, it will certainly involve a lot of restricting elements and difficulties which need to be considered and solved step by step, such as the split-flow of surplus teachers, the layout of urban secondary schools, the optimization of educational resources, how to support rural poor students and so on.

\section{References}

(2008). Educational Equality: The Lookout Tower for Social Harmony. [Online] Available: http://news.qq.com. December.

Li, Shaoyuan. (2003). The Challenge of Urbanization for the Development of Rural Education. Educational Science of the Copy Press of Renmin University. (5): p23.

Liu, Ran. Lu, Cheng. (2001). New Problems Facing Rural Compulsory Education. Middle and Primary School Education. (9): p12.

R\&D Center of Shanghai Academy of Educational Science (2003). Progress and Problems in China's Popularization of Compulsory Education. Middle and Primary School Education. (3): p10. 